\title{
ANALISIS TINGKAT KEPUASAN WISATAWAN DOMESTIK TERHADAP PELAYANAN RESERVASI TIKET PESAWAT DI GARUDA INDONESIA DENPASAR, BALI
}

\author{
Godang \\ I Made Sendra \\ Yayu Indrawati \\ Email : godang.is@gmail.com \\ PS. S1 Industri Perjalanan Wisata \\ Fakultas Pariwisata UNUD
}

\begin{abstract}
Bali, whose name is identical with tourism, is one of the tourist destination in Indonesia, whose name has been synonymous with tourism. Airlines, which one of them is Garuda Indonesia, became one of the factors that developed tourism in Bali. The background of this research due to complaints from tourists who made a reservation at Garuda Indonesia.

The purpose of this study is to determine the satisfaction of domestic touristto ticket reservation service at Garuda Indonesia, so we can know which variables that must be maintained and enhanced.

This research was conducted using the method of Importance-Performance Analysis by distributing questionnaires to 60 respondents domestic tourist who make ticket reservations at Garuda Indonesia which service dimensions studied are reliability, responsiveness, assurance, empathy, and tangible.

Based on the research that has been done, it could be concluded that the overall rating is not satisfied with the service provided by the staff of Garuda Indonesia, both in terms of reliability, responsiveness, assurance, empathy, and tangible so that the performance needs to be improved.Garuda Indonesia can improve and enhance the service quality of staff and domestic tourists satisfaction by looking the sequence of priority in airline ticket reservation service indicator
\end{abstract}

Keywords: Service quality.

\section{PENDAHULUAN}

Bali sebagai tourist destination utama di Indonesia namanya sudah identik dengan pariwisata. Sejalan dengan perkembangan pariwisata dunia dimana mobilitas manusia semakin cepat, Bali mampu menempatkan diri sebagai daerah tujuan wisata yang memiliki daya tarik tersendiri. didukung dengan penyediaan sarana dan prasarana pariwisata sehingga tersedia komponen-komponen pariwisata yang diperlukan yaitu sesuatu yang dapat dilihat (something to see), sesuatu yang dapat dikerjakan (something to do), dan sesuatu yang dapat dibeli (something to buy).

Banyak upaya yang dilakukan oleh pemerintah setempat untuk memajukan dan mengembangkan segala potensi pariwisata yang ada di Pulau Bali ini. Hal ini terlihat dari dikeluarkannya kebijakan-kebijakan oleh pemerintah setempat untuk memajukan pariwisata di Pulau Bali (Perda No 2 Tahun 2012 Tentang Kepariwisataan Budaya Bali). Kebijakan-kebijakan ini diharapkan dapat mengundang para investor, mengatur iklim usaha pariwisata, menjaga segala potensi wisata dan alam pendukungnya, serta meningkatkan peran masyarakat dalam memajukan sektor kepariwisataan tersebut.

Untuk meningkatkan jumlah kunjungan wisatawan ke Bali diperlukan kerjasama terpadu antara pemerintah sebagai pemegang kebijaksanaan, pihak swasta sebagai pemegang modal dan masyarakat setempat sebagai pendukung pariwisata. Pihak swasta yang dimaksud salah satunya adalah maskapai penerbangan yang banyak membantu pemerintah dalam mempromosikan daerah tujuan wisata dan memberikan informasi 
mengenai situasi dan kondisi yang benar di Bali serta sebagai perantara di antara perusahaan-perusahaan industri dan wisatawan potensial.

Salah satu maskapai penerbangan yang ada di Indonesia adalah Garuda Indonesia. Jumlah wisatawan domestik yang menggunakan Garuda Indonesia dari Denpasar bersifat fluktuatif atau tidak stabil. Pada tahun 2009 sampai 2011 mengalami peningkatan, tetapi mengalami penurunan di tahun 2012, dan mengalami peningkatan kembali pada tahun 2013. Walaupun bersifat fluktuatif, Garuda Indonesia menempati urutan pertama dalam hal jumlah wisatawan domestik yang menggunakan jasa penerbangan jika dibandingkan dengan kedua kompetitornya, yaitu Lion Air dan Air Asia. Sedangkan jika dilihat dari jumlah dan rata-rata pertumbuhannya, Garuda Indonesia berada diurutan terakhir setelah Air Asia dan Lion Air.

Persaingan harga yang lebih murah dan ekonomis diberikan oleh kedua kompetitor Garuda Indonesia menjadi salah satu faktor penghambat pertumbuhan Garuda Indonesia. Selain itu, ada komplain dari wisatawan domestik terhadap kinerja staf reservasi tiket pesawat.

Berdasarkan permasalahan di atas, penulis ingin menganalisa tingkat kepuasan wisatawan terhadap pelayanan reservasi tiket pesawat di Garuda Indonesia Denpasar, Bali.

\section{TINJAUAN PUSTAKA}

Wisatawan domestik yang dimaksudkan dalam penelitian ini adalah orang yang melakukan perjalanan wisata di negaranya sendiri yang dimana daerah tujuan wisata yang dituju pun masih berada dalam negaranya.

Tiket pesawat merupakan sebuah tiket yang digunakan sebagai kontrak yang sah antara perusahaan penerbangan dan penumpang, memberikan hak pembawa, dengan tarif menyatakan, untuk melakukan perjalanan pada satu atau lebih penerbangan tertentu.

Untuk pengertian reservasi dalam penelitian ini adalah komunikasi secara lisan kepada pegawai maskapai penerbangan dari pelanggan yang melakukan pemesanan tempat duduk dalam pesawat udara secara manual.

Pengertian kualitas pelayanan menurut Supranto (2006 : 208) adalah keunikan dan keunggulan yang diperlihatkan oleh jasa, apakah sudah sesuai dengan harapan dan keinginan pelanggan. Menurut Kotler (dalam Majid , 2009 : 46), ada lima kriteria penentu kualitas jasa, yaitu:

1. Keandalan (Reliability), yaitu kemampuan perusahaan untuk melakukan pelayanan sesuai yang dijanjikan dengan segera, akurat, dan memuaskan.

2. Ketanggapan (Responsiveness), yaitu kemampuan perusahaan untuk menolong pelanggan dan ketersediaan untuk melayani pelanggan dengan baik.

3. Keyakinan / Jaminan (Assurance), yaitu pengetahuan, kesopanan petugas, serta sifatnya yang dapat dipercaya sehingga pelanggan terbebas dari resiko.

4. Kepedulian / Empati (Empathy), yaitu rasa peduli untuk memberikan perhatian secara individual kepada pelanggan, memahami kebutuhan pelanggan, serta kemudahan untuk dihubungi.

5. Penampilan / Bukti Fisik (Tangible), yaitu meliputi fasilitas fisik, perlengkapan karyawan, dan sarana komunikasi.

Menurut Kotler (dalam Majid, 2009 :

50) kepuasan pelanggan adalah perasaan senang atau kecewa seseorang yang muncul setelah membandingkan antara persepsi/kesannya terhadap kinerja (hasil) suatu produk dan harapan-harapannya.

\section{METODE PENELITIAN}

Penelitian ini dilakukan di Garuda Indonesia Denpasar, Bali. Penelitian dilakukan Garuda Indonesia karena merupakan salah satu maskapai terbesar yang ada di Indonesia, khususnya di Bali. Selain itu lokasinya strategis di pusat kota Denpasar sehingga menarik banyak wisatawan untuk menggunakan jasanya.

Teknik penentuan sampel dilakukan dengan cara purposive sampling yang pengambilannya secara accidental sampling. Teknik analisis data menggunakan metode analisis Importance-Performance Analysis dengan menggunakan skala 5 tingkat (Likert) untuk skor kinerja dan skor kepentingan.

Tingkat kesesuaian merupakan hasil perbandingan antara skor kinerja dan skor kepentingan. Jika tingkat kesesuaian reponden sama dengan 100 persen maka wisatawan merasa puas, jika tingkat kesesuaian responden di atas 100 persen menyatakan 
bahwa wisatawan sangat puas terhadap pelayanan yang berarti kualitas pelayanan sangat baik dan jika di bawah 100 persen menyatakan wisatawan tidak puas dengan pelayanan yang berarti kualitas pelayanan kurang baik atau tidak baik. Tingkat kesesuaian inilah yang akan menentukan urutan prioritas peningkatan faktor-faktor yang memperngaruhi kepuasaan wisatawan.

Selanjutnya agar dapat mengetahui letak indikator dalam diagram cartesius, maka telebih dahulu menentukan dua buah titik $\overline{\bar{X}}$ dan $\overline{\bar{Y}}$ yang berpotongan membatasi empat bagian dalam diagram cartesius. Perhitungan $\overline{\bar{X}}$ merupakan rata-rata dari rata-rata skor tingkat kinerja seluruh indikator yang mempengaruhi kepuasan wisatawan, sedangkan perhitungan $\overline{\bar{Y}}$ yaitu rata-rata dari rata-rata skor tingkat kepentingan dan seluruh indikator yang mempengaruhi kepuasan wisatawan.

\section{HASIL DAN PEMBAHASAN}

Garuda Indonesia adalah maskapai penerbangan Indonesia yang berkonsep sebagai full service airline (maskapai dengan pelayanan penuh). Saat ini Garuda Indonesia mengoperasikan 82 armada untuk melayani 33 rute domestik dan 18 rute internasional termasuk Asia (Regional Asia Tenggara, Timur Tengah, China, Jepang dan Korea Selatan), Australia serta Eropa (Belanda).

Sebagai bentuk kepeduliannya akan keselamatan, Garuda Indonesia telah mendapatkan sertifikasi IATA Operational Safety Audit (IOSA). Hal ini membuktikan bahwa maskapai ini telah memenuhi standar internasional di bidang keselamatan dan keamanan.

Berdasarkan metode J. Supranto, penelitian yang menggunakan analisis kualitiatif-kuantitatif, responden yang akan diberikan kuesioner sebanyak 60 orang. Responden yang dimaksud dalam penelitian ini adalah wisatawan domestik yang telah melakukan reservasi tiket secara manual di Garuda Indonesia. Kuesioner yang telah disebarkan kepada 60 orang wisatawan domestik yang menjadi reponden terdiri dari beberapa faktor yaitu jenis kelamin, tingkat usia dan frekuensi melakukan reservasi tiket.

$$
\text { Untuk mengetahui karakteristik }
$$
wisatawan yang melakukan reservasi tiket secara manual di Garuda Indonesia dapat dilihat dari Tabel 1.

Tabel 1. Karakteristik Wisatawan Domestik

\begin{tabular}{cc}
\hline Karakteristik & Persentase (\%) \\
\hline Jenis kelamin : & \\
a. Laki-laki & 53,33 \\
b. Perempuan & 46,67 \\
\hline Tingkat Usia & \\
a. $\leq 20$ tahun & 16,67 \\
b. 21-30 tahun & 65 \\
c. $31-40$ tahun & 10 \\
d. $\geq 41$ tahun & 8,33 \\
\hline Frekuensi & \\
a. 1 kali & 25 \\
b. 2 kali & 68,33 \\
c. $\geq 3$ kali & 6,67 \\
\hline
\end{tabular}

Berdasarkan hasil penelitian mengenai analisis tingkat kepentingan dan kepuasan wisatawan yang melakukan reservasi tiket di Garuda Indonesia yaitu sebanyak 60 orang responden, diperoleh data mengenai tingkat kepentingan dan kepuasan wisatawan yang telah ditabulasi ke dalam tabel sebagai berikut. 
Vol. 2 No. 2, 2014

Tabel 2. Hasil Penelitian Responden terhadap Kualitas Pelayanan Reservasi Tiket dan Tingkat Kepentingan Wisatawan Garuda Indonesia

\begin{tabular}{ccc}
\hline $\begin{array}{c}\text { Variabel dan Indikator } \\
\text { Pelayanan }\end{array}$ & $\begin{array}{c}\text { Skor Kinerja } \\
(\mathrm{X})\end{array}$ & $\begin{array}{c}\text { Skor } \\
\text { Kepentingan } \\
(\mathrm{Y})\end{array}$ \\
\hline A1 & 246 & 288 \\
A2 & 241 & 281 \\
\hline B1 & 238 & 276 \\
B2 & 227 & 281 \\
B3 & 229 & 279 \\
\hline C1 & 241 & 284 \\
C2 & 241 & 284 \\
C3 & 228 & 271 \\
\hline D1 & 211 & 265 \\
D2 & 228 & 278 \\
\hline E1 & 231 & 278 \\
E2 & 247 & 274 \\
\hline
\end{tabular}

Keterangan :

A1 : Melayani wisatawan secara cepat dantepat

A2 : Kemampuan staf dalam menghandel wisatawan

B1 : Kemampuan staf cepat tanggap terhadap kebutuhan wisatawan

B2 : Kemampuan staf dalam menindaklanjuti keluhan wisatawan

B3 : Kemampuan staf dalam meberikan informasi secara singkat dan jelas

$\mathrm{C} 1$ : Pengetahuan dan keterampilan staf dalam memberikan pelayanan

C2 : Keramahtamahan dan kesopanan stafdalam memberikan pelayanan

C3 : Melakukan komunikasi yang efektifdengan wisatawan

D1 : Kemampuan staf dalam memberikan perhatian secara individual kepada wisatawan

D2 : Bertanggung jawab terhadap keamanan dan kenyamanan wisatawan

E1 : Sarana komunikasi dan fasilitaspenunjang

E2 : Kebersihan dan kerapihan staf

Setelah diperoleh skor kinerja (X) dan skor kepentingan $(\mathrm{Y})$, selanjutnya mencari rata-rata skor kinerja, skor kepentingan dan tingkat kesesuaian dengan hasil sebagai berikut.

Tabel 3. Rata-Rata Penilaian Tingkat Kinerja, Tingkat Kepentingan dan Tingkat Kesesuaian dari Indikator Pelayanan

\begin{tabular}{cccc}
\hline $\begin{array}{c}\text { Variabel dan Indikator } \\
\text { Pelayanan }\end{array}$ & $\overline{\mathrm{X}}$ & $\overline{\mathrm{Y}}$ & $\begin{array}{c}\text { Tingkat Kesesuaian } \\
(\%)\end{array}$ \\
\hline A1 & 4,10 & 4,80 & 85,42 \\
A2 & 4,02 & 4,68 & 85,77 \\
\hline B1 & 3,97 & 4,60 & 86,23 \\
B2 & 3,78 & 4,68 & 80,78 \\
\hline
\end{tabular}




\begin{tabular}{cccc}
\hline B3 & 3,82 & 4,65 & 82,08 \\
\hline C1 & 4,02 & 4,73 & 84,86 \\
C2 & 4,02 & 4,73 & 84,86 \\
C3 & 3,80 & 4,52 & 84,13 \\
\hline D1 & 3,52 & 4,42 & 79,62 \\
D2 & 3,80 & 4,63 & 82,01 \\
\hline E1 & 3,85 & 4,63 & 83,09 \\
E2 & 4,12 & 4,57 & 90,15 \\
\hline TOTAL & 46,8 & 55,65 & 1009 \\
\hline RATA-RATA & 3,9 & 4,64 & 84,08 \\
\hline
\end{tabular}

Berdasarkan perhitungan menggunakan rumus, didapat nilai $\overline{\bar{X}}=3,9$ dan $\overline{\bar{Y}}=4,64$ yang digunakan untuk membatasi empat bagian dalam diagram cartesius. Letak indikator yang mempengaruhi kepuasan wisatawan saat melakukan reservasi tiket pada Garuda Indonesia dapat dilihat dalam diagram cartesius berikut.

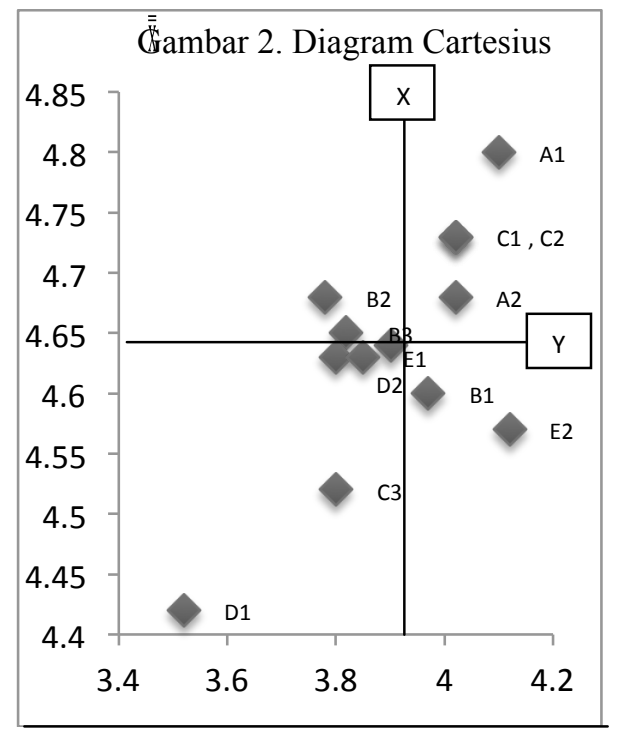

Garis Y pada diagram tersebut merupakan batas tingkat kepentingan masing-masing faktor atau indikator pelayanan menurut persepsi wisatawan. Garis tersebut membagi diagram menjadi dua bagian yaitu hasil pengukuran terhadap indikator pelayanan. Di atas garis $\mathrm{Y}$ maka indikator dari pelayanan tersebut dianggap penting oleh wisatawan Garuda Indonesia, antara lain:

1. Melayani wisatawan secara cepat dan tepat (A1)

2. Kemampuan staf dalam menghandel wisatawan (A2)

3. Kemampuan staf dalam menindaklanjuti keluhan wisatawan (B2)
4. Kemampuan staf dalam memberikan informasi secara singkat dan jelas (B3)

5. Pengetahuan dan keterampilan staf dalam memberikan pelayanan $(\mathrm{C} 1)$

6. Keramahtamahan dan kesopanan staf dalam memberikan pelayanan $(\mathrm{C} 2)$

Jika hasil pengukuran terhadap indikatorindikator pelayanan terletak di bawah garis $\mathrm{Y}$ maka indikator-indikator pelayanan yang dianggap kurang penting oleh wisatawan, antara lain:

1. Kemampuan staf cepat tanggap terhadap kebutuhan wisatawan (B1)

2. Melakukan komunikasi yang efektif dengan wisatawan (C3)

3. Kemampuan staf dalam memberikan perhatian secara individual kepada wisatawan (D1)

4. Bertanggung jawab terhadap keamanan dan kenyamanan wisatawan (D2)

5. Sarana komunikasi dan fasilitas penunjang (E1)

6. Kebersihan dan kerapihan staf (E2)

Letak indikator-indikator dalam diagram cartesius tersebut dapat dijelaskan sebagai berikut.

1. Kuadran A

Indikator dalam kuadran ini, yang perlu mendapatkan prioritas utama oleh staf Garuda Indonesia karena keberadaannya dianggap penting oleh wisatawan, sedangkan kinerja atau pelaksanaannya masih belum memuaskan. Adapun indikator yang berada pada kuadran A diantaranya, kemampuan staf dalam menindaklanjuti keluhan wisatawan (B2) dan kemampuan staf dalam memberikan informasi secara singkat dan jelas (B3)

2. Kuadran B

Indikator pada kuadran ini dianggap penting oleh wisatawan dan pelaksanannya telah sesuai harapan 
wisatawan sehingga perlu dipertahankan prestasinya oleh staf Garuda Indonesia. Adapun indikator yang berada pada kuadran B, yaitu melayani wisatawan secara cepat dan tepat (A1), kemampuan staf dalam menghandel wisatawan (A2), pengetahuan dan keterampilan staf dalam memberikan pelayanan (C1), keramahtamahan dan kesopanan staf dalam memberikan pelayanan (C2)

3. Kuadran $\mathrm{C}$

Pada kuadran ini, indikator yang dinilai kurang penting oleh wisatawan sedangkan kinerja atau pelaksanaanya oleh staf Garuda Indonesia biasa-biasa saja. Indikator yang termasuk dalam kuadran yang memiliki prioritas rendah ini diantaranya, melakukan komunikasi yang efektif dengan wisatawan (C3), kemampuan staf dalam memberikan perhatian secara individual kepada wisatawan (D1), dan bertanggung jawab terhadap keamanan dan kenyamanan wisatawan (D2), serta sarana komunikasi dan fasilitas penunjang (E1)

4. Kuadran D

Indikator pada kuadran ini dinilai kurang penting bagi wisatawan namun pelaksanaannya berlebihan. Adapun indikator yang berada pada kuadran D, yaitu kemampuan staf cepat tanggap terhadap kebutuhan wisatawan (B1) dan indikator lainnya adalah kebersihan dan kerapihan staf (E2)

Faktor yang memiliki tingkat kesesuaian paling rendah merupakan faktor yang paling perlu mendapat prioritas utama, begitu juga dengan indikator lainnya yang tingkat kesesuaiannya semakin tinggi, maka urutan prioritasnya pun akan turun.

Untuk kesesuaian dan urutan prioritas tersebut akan ditampilkan pada Tabel 4.

Tabel 4. Prioritas Indikator Pelayanan Berdasarkan Tingkat Kesesuaian

\begin{tabular}{ccc}
\hline Variabel dan Indikator Pelayanan & Tingkat Kesesuaian (\%) & Prioritas \\
\hline A1 & 85,42 & 9 \\
A2 & 85,77 & 10 \\
\hline B1 & 86,23 & 11 \\
B2 & 80,78 & 2 \\
B3 & 82,08 & 4 \\
\hline C1 & 84,86 & 7 \\
C2 & 84,86 & 8 \\
C3 & 84,13 & 6 \\
\hline D1 & 79,62 & 1 \\
D2 & 82,01 & 3 \\
\hline E1 & 83,09 & 5 \\
E2 & 90,15 & 12 \\
\hline
\end{tabular}

\section{SIMPULAN DAN SARAN}

Berdasarkan pembahasan tingkat kepuasan wisatawan yang melakukan reservasi tiket pada Garuda Indonesia dengan menggunakan teknik analisis tingkat kepentingan dan kinerja (Importance Performance Analysis) dari jumlah responden 60 orang maka dapat diambil beberapa kesimpulan sebagai berikut :

1. Hasil penilaian responden terhadap kualitas pelayanan reservasi tiket wisatawan domestic pada Garuda Indonesia berdasarkan kinerja karyawannya, bobot tertinggi terletak pada indikator kebersihan dan kerapihan staf
(E2) dengan skor 247 dan yang terendah terletak pada kemampuan staf dalam memberikan perhatian secara individual kepada wisatawan (D1) dengan skor 211.

2. Hasil penilaian responden terhadap kualitas pelayanan reservasi tiket wisatawan domestik pada Garuda Indonesia berdasarkan kepentingannya, bobot tertinggi terletak pada indikator melayani wisatawan secara cepat dan tepat (A1) dengan skor 288 dan yang terendah terletak pada indikator kemampuan staf dalam memberikan perhatian secara individual kepada wisatawan (D1) dengan skor 265. 
3. Wisatawan yang melakukan reservasi tiket pada Garuda Indonesia merasa tidak puas terhadap kinerja atau pelayanan yang diberikan oleh pihak perusahaan, karena nilai tingkat kesesuaian di bawah 100 persen, yaitu $84,08 \%$.

4. Tingkat kesesuaian tertinggi berada pada indikator kebersihan dan kerapihan staf (E2) dengan 90,15 persen sedangkan tingkat kesesuaian terendah berada pada indikator kemampuan staf dalam memberikan perhatian secara individual kepada wisatawan (D1) dengan 79,62 persen.

5. Rata-rata dari rata-rata skor tingkat kinerja seluruh indikator yang mempengaruhi kepuasan wisatawan domestik sebesar 3,9 sedangkan rata-rata dari rata-rata skor tingkat kepentingan dari seluruh indikator yang mempengaruhi kepuasan wisatawan domestic sebesar 4,64.

6. Indikator-indikator yang dinilai penting dan perlu dipertahankan kinerjanya untuk meningkatkan kepuasan wisatawan domestik adalah melayani wisatawan secara cepat dan tepat (A1), kemampuan staf dalam menghandel wisatawan (A2), pengetahuan dan keterampilan staf dalam memberikan pelayanan (C1), dan keramahtamahan dan kesopanan staf dalam memberikan pelayanan $(\mathrm{C} 2)$.

7. Indikator yang perlu mendapatkan perhatian lebih dari pihak perusahaan adalah kemampuan staf dalam menindaklanjuti keluhan wisatawan (B2) dan kemampuan staf dalam memberikan informasi secara singkat dan jelas (B3).

8. Berdasarkan tingkat kesesuaian, indikator yang perlu mendapatkan prioritas utama dari pihak perusahaan adalah kemampuan staf dalam memberikan perhatian secara individual kepada wisatawan (D1) karena memiliki nilai tingkat kesesuaian terendah, sedangkan untuk indikator kebersihan dan kerapihan staf (E2) berada pada prioritas terakhir karena memiliki nilai tingkat kesesuaian tertinggi namun harus tetap diperhatikan karena wisatawan masih belum puas.

\section{Saran}

Berdasarkan simpulan tersebut, maka dapat dikemukakan beberapa saran yang sekiranya dapat bermanfaat bagi Garuda
Indonesia terutama dalam pelayanan reservasi tiket, yakni sebagai berikut.

1. Dalam memberikan pelayanan kepada wisatawan saat melakukan reservasi tiket, hendaknya kemampuan staf dalam memberikan informasi harus lebih jelas dan singkat. Selainitu kemampuan staf dalam menindaklanjuti keluhan lebih ditingkatkan karena indikator ini dinilai penting oleh wisatawan dan kinerjanya masih jauh dari memuaskan. Oleh karena itu, kedua indikator ini harus menjadi prioritas utama untuk ditingkatkan oleh staf reservasi tiket Garuda Indonesia saat wisatawan melakukan reservasi.

2. Disarankan agar pihak manajemen Garuda Indonesia memberikan guest comment ke wisatawan setiap selesai melakukan reservasi tiket, walaupun sudah ada call center yang melayani keluhan wisatawan namun masih kurang efektif.

3. Pihak Garuda Indonesia hendaknya melakukan evaluasi terhadap kinerja stafnya secara berkala, baik dilakukan setiap bulan atau tiap tiga bulan dengan harapan untuk mendapatkan masukanmasukan dari wisatawan mengenai kepuasan dan keluhan sehingga dapat menjadi bahan pertimbangan bagi pihak manajemen agar dapat meningkatkan kualitas pelayanan reservasi di masa yang akan datang.

\section{DAFTAR PUSTAKA}

Majid, Suharto Abdul. 2009. Customer Service dalam Bisnis Jasa Transportasi. Jakarta : Rajagrafindo Persada.

Supranto, Johanes. 2001. Statistik, Teori, dan Aplikasi Jilid 1. Jakarta: Erlangga.

Supranto, Johanes. 2006. Pengukuran Tingkat Kepuasan Pelanggan untuk Menaikkan Pangsa Pasar. Jakarta: Rineka Cipta. 